\title{
Finite Element Analysis of Three Patterns Of Internal Fixation of the Mandibular Subcondylar Fractures (Comparative Study)
}

\author{
Original \\ Mohammed, Mohammed Abdelwahab', Sleem Heba Abdulwahed', Metwally \\ Article kamal ghamry \\ ${ }^{1}$ OMFS Nasser in stitute hospital \\ ${ }^{2}$ Department of Oral and Maxillofacial Surgery Ain Shams University. \\ ${ }^{3}$ Faculty of Engineering, Beni-Suef University New Beni-Suef City, Shark El-Nile
}

\begin{abstract}
Aim: The aim of our study is to compare three plating techniques (single 2.3 plate, two mini-plates and rhomboid plate) biomechanically, and to conclude which one is the most stable in the treatment of subcondylar fractures.

Materials and methods: 3D model of human mandible was constructed on work bench solid works program and manipulated to mimic true subcondylar fracture with proximal and distal parts fully separated, three designs of plating techniques was constructed and wrapped on the mandible model, the final three models was exported to FEM software as solid models with masticatory muscles molded bilaterally in addition to contralateral molar clenching task, linear elastic solution was constructed for each model and results was assigned according to von misses stresses upon hardware, jaw bone and total model deformation in each configuration..
\end{abstract}

Result: Double plating 2.0 design showed optimal results compared to rhombic plate and single 2.3 plates.

Conclusion: Double plating 2.0 design is the gold standard and the best method of fixation for tha mandibular subcondylar fractures provided that available space is enough for the application of the two plates.

Key Words: Finite element analysis, ORIF, subcondylar fracture.

Received: 12 October 2018, Accepted: 26 November 2018

Corresponding Author: Abdelwahab M., Oral and Maxillofacial Surgery Department Nasser Institute Hospital, Cairo, Egypt, E-mail: markwitz8@gmail.com

ISSN: 2090-097X, October 2018, Vol. 9, No. 4

\section{INTRODUCTION}

Treating facial skeleton fractures is considered to be an important component of oral and maxillofacial surgical practice (1). Essentially, this treatment has changed from closed reduction to open reduction and internal fixation (ORIF) and widely accepted as best practice (1).

The treatment for condylar neck and subcondylar fractures remains one of the most controversial issues of mandible surgery despite the high incidence of these fractures. Mandible condylar fractures are frequent accounting for $25-45 \%$ of all mandibular fractures(2).

Condylar fractures are often resulting from indirect forces that transmitted along the mandible from distant sites such as the angle, body or symphysis. It usually occurs when the mouth is opened at the time of injury so that some of the impacting force is transmitted along the mandible to its weakest area to condylar head(3).

For long time, closed reduction has been the preferred treatment, but closed treatment requires varying periods of maxillomandibular fixation and long term complications like pain, ankylosis, internal derangement of (TMJ), as well as the inadequate restoration of the vertical height of the ramus, can possibly occur. The debate continues over how to best manage subcondylar fractures and the question of which fractures should be treated surgically has yet to be answered.

However, in recent years, due to the development of the osteosynthesis technique and the refinement of surgical techniques, the attitude towards the treatment of a condylar neck fracture has changed from an exclusively nonsurgical approach toward surgical treatment. Recently, anatomic reduction and early mobilization of the jaw following surgery have been considered important for the functional rehabilitation of the TMJ(4).

Treatment of condylar fractures with rigid internal fixation has made significant advances over the past years due to improved understanding of biomechanical principles, advances in fixation technique and instrumentation and due to scientifically based research of treatment outcome. The therapeutic goals in condylar fracture management are to re-establish premorbid anatomy, to provide fracture 
stabilization and to restore the functionality with least morbidity. This can be achieved via an open approach to the joint area and osteosynthesis.(5)

The biomechanical function of teeth generally results in stresses, which are transferred to mandible and condyles producing strains and stresses in all of them. Understanding the nature of strain and stress distribution is essential for better diagnosis and treatment of all maxillofacial diseases and restoration of masticatory function (6). Unfortunately, the stresses cannot be measured directly in a non-destructive way. The number of direct studies on the masticatory system is limited, because of its difficulties (6).

In recent years, a number of research teams have used the finite element method to conduct biomechanical analysis on condylar base and neck fractures osteosynthesis. For example, Parascandolo et al. and Wagner et al. analyzed the behavior of single and double plates $(7,8)$ Aquilina et al. and De Jesus et al. analyzed three methods of condylar osteosynthesis (9). Kozakiewicz et al. presented an A-shape plate to fixate condylar base fracture (10).and Loai Hijazi et al who described effect of various clenching task upon condylar fracture(11).

\section{The aims of this study were as follows:}

1. To create a biomechanical three-dimensional model of mandible with subcondylar fracture fixated with three patterns of osteosynthesis (single 2.3, double 2.0 miniplates, and rhombic plate).

2. To analyze biomechanical behavior of the osteosynthesis, bone surrounding the Screws using finite element method.

\section{MATERIALS AND METHODS:}

\section{Construction of the models:}

Three dimensional model of human mandible was constructed on workbench Solidworks software program. The model was manipulated to mimic a true subcondylar fracture. Also three osteosynthesis designs was constructed on the same program (two straight four holes noncompression miniplate with eight corresponding screws, one straight four holes 2.3 non-compression plate with four corresponding screws and rhombic plate five holes with five corresponding screws). . The screw length was $5 \mathrm{~mm}$ (monocortical) in both double plate 2.0 design and rhombic plate versus $8 \mathrm{~mm}$ (bicortical) in the single plate 2.3 design(12). Three patterns of fixation were investigated, each having two holes along either side of the fracture line. The first pattern was a single 2.3 plate placed along the posterior border of the mandible in the axis of the condylar neck, the second pattern was two miniplate 2.0 one placed along the posterior border of the mandible and the second plate was placed to run parallel under the sigmoid notch(13), the third pattern involved a rhombic plate was placed to adapt the condylar anatomy(14). The plates were virtually bent (using Solidworks software) fitting the morphology of the condylar neck to simulate the clinical situation of bending the plates manually before fixation. Plates were located slightly off the bony surface with no contact between the plates and bone ( $0.3-\mathrm{mm}$ distance). This lack of contact was important for test of plates as a load bearing device. The screw-to-plate and screw-to-bone interfacial conditions were assumed to be bonded according to previously published protocol (11). Each fixation pattern was applied on a solid three dimensional model, then models was exported to FEM software (Swanson, P.G., "ANSYS, Inc. Theory", Theoretical Manual, Release 19.0, U.S.A., 1 2017). .

\section{Material specifications and (FEM):}

SOLID187 element, which is a high-order 3D, 10-node element, was used to simulate the mandible, plate, and the screws. A solid element, SOLID187, has a quadratic displacement behavior and is used to model irregular meshes in ANSYS. The element is defined by 10 nodes having three degrees of freedom at each node: translations in the nodal $\mathrm{x}, \mathrm{y}$, and $\mathrm{z}$ directions.

The finite element mesh of the single 2.3 model consisted of (57437) elements and (104279) nodes (fig1). The finite element mesh of the double 2.0 plate model consisted of (207655) elements and (360119) nodes. The finite element mesh of the rhombic plate model consisted of (157280) elements and (272203) nodes.

The models were considered to be a non-homogeneous with eight different material properties (isotropic and linear elastic). Properties were assigned on the basis of CT density (Hounsfield units HU) as in previously published protocols (1) as referred in Table 1 .

\section{Muscle forces and boundary conditions:}

In order to obtain meaningful results, boundary conditions should represent as closely as possible the actual reality of support condition of the model under consideration. In most commercially available FE software, physical constraints are invoked by zero displacements and/or rotations at selected user-defined nodes. Standard fixities were applied to the boundaries of the condylar process of the mandibular model as illustrated in Fig2. 


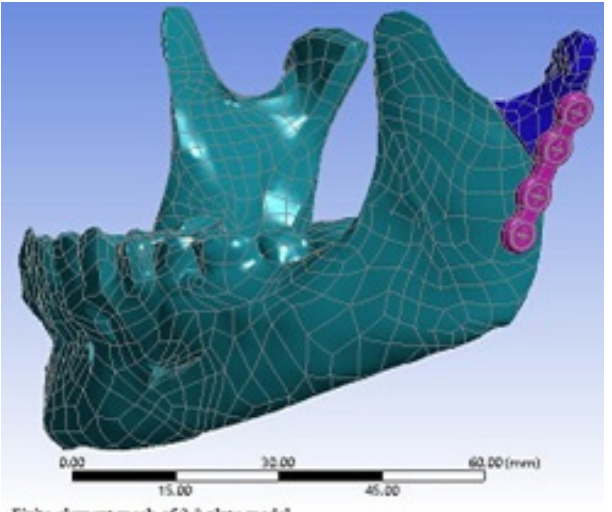

Finte element mesh of 2.3 slate =odel

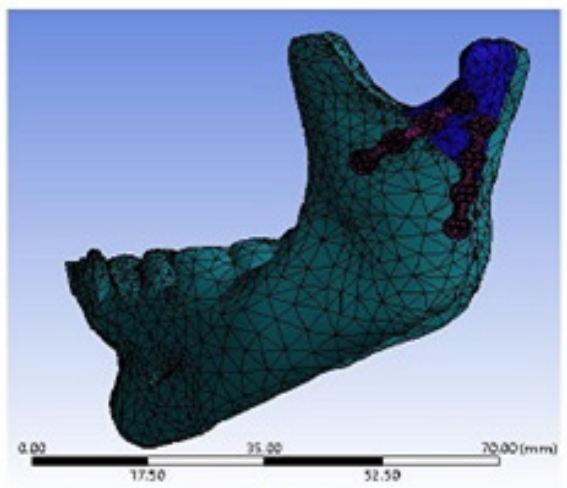

Finhe eirment mesh of doutic 2.0 plate model

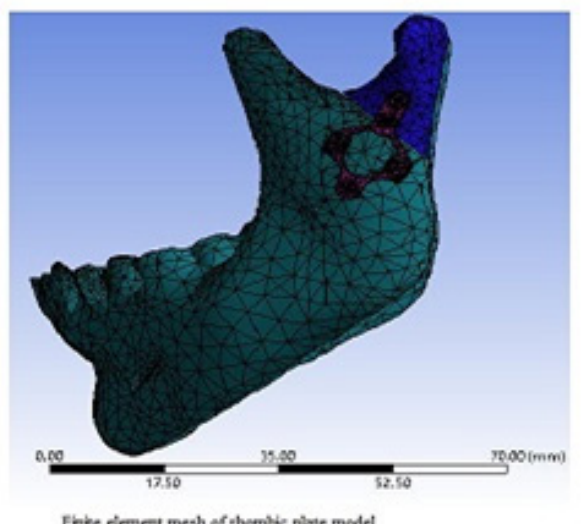

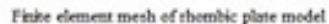

Fig. 1: Finite element mesh of the three different models

Table 1: Materials properties of elements in the finite element models in relation to the distribution of (HUS) on (CT).

\begin{tabular}{ccc}
\hline $\begin{array}{c}\text { Material properties of } \\
\text { elements }\end{array}$ & $\begin{array}{c}\text { Young's modulus } \\
(\mathrm{MPa})\end{array}$ & Density (T/mm3) \\
\hline MAT 1 & 1572.0 & $2.508 \mathrm{e}-10$ \\
MAT 2 & 1868.6 & $2.916 \mathrm{e}-10$ \\
MAT 3 & 2223.4 & $3.325 \mathrm{e}-10$ \\
MAT 4 & $10,786.8$ & $1.094 \mathrm{e}-09$ \\
MAT 5 & $21,734.2$ & $1.855 \mathrm{e}-09$ \\
MAT 6 & $27,082.2$ & $2.190 \mathrm{e}-09$ \\
MAT 7 & $32,704.3$ & $2.525 \mathrm{e}-09$ \\
MAT 8 & $38,575.4$ & $2.860 \mathrm{e}-09$ \\
\hline
\end{tabular}

The loading conditions illustrated in(table2) pertained to seven principal muscles: the superficial masseter (SM), deep masseter (DM), medial pterygoid (MP), inferior lateral pterygoid (ILP), anterior temporalis (AT), middle temporalis (MT), and posterior temporalis (PT). Clenching task was applied to contralateral side (right side) upon molar units because of the resultant high von misses stress (11).

Table 2: The magnitudes of applied muscle forces upon mandibular models

\begin{tabular}{ccccccccc}
\hline & \multicolumn{7}{c}{ Muscular forces (N) } \\
\cline { 2 - 8 } Direction & \multicolumn{7}{c}{ Right } \\
\cline { 2 - 9 } & SM & DM & MP & AT & MT & PT & ILP & ILP \\
\hline $\begin{array}{c}\text { Resultant } \\
\text { Force }\end{array}$ & 137.1 & 58.8 & 146.9 & 115.4 & 63.1 & 44.6 & 20.1 & 43.5 \\
Fx & -28.4 & -32.1 & 71.4 & -17.2 & -14.0 & -9.3 & 12.6 & -27.4 \\
Fy & 121.2 & 44.5 & 116.1 & 114.0 & 52.8 & 21.1 & -3.5 & -7.6 \\
Fz & 57.4 & -21.0 & 54.8 & 5.1 & -31.5 & -38.1 & 15.2 & 32.9 \\
\hline
\end{tabular}

\section{Analysis of results:}

The models were evaluated using a ratio in $\mathrm{MPa}(\mathrm{N} /$ $\mathrm{mm} 2$ ). The tension fields over bone and plates were evaluated using Von Misses analysis (maximum stress). A color coded scale with von Misses stress and strain values (varying in MPa and $\mu \mathrm{m}$ ) was used and each color map presented a specific scale according to the result under study. After solving each model, the relative Von Misses (VM) stresses and strains were also calculated for each model upon plates, bone surrounding screws, and interfragmentary motion between the bony fragments.

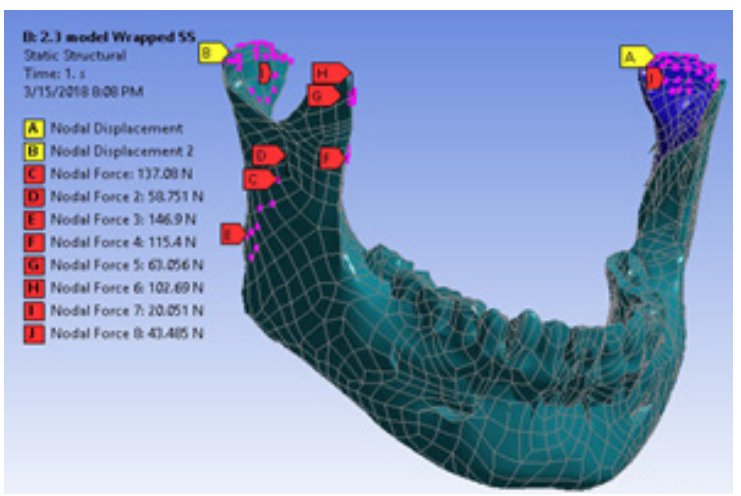

Fig. 2: Muscular loads and boundary conditions

\section{RESULTS:}

\section{Von Misses stresses upon titanium plates:}

Results illustrated in fig (3) showed that VM stresses for the 2.3 plate was $(750 \mathrm{MPa}), \mathrm{VM}$ stresses for the double 2.0 plate was $(450 \mathrm{MPa})$, and VM stresses for rhombic plate was $(650 \mathrm{MPa})$.

\section{Von Misses stresses upon bone surrounding screws:}

Results illustrated in fig (4) shows that VM stresses for 
the 2.3 configuration model is $(49.75 \mathrm{MPa}), \mathrm{VM}$ stresses for the double 2.0 configuration model is $(31.67 \mathrm{MPa})$, and VM stresses for rhombic plate configuration model is (42.7 $\mathrm{MPa})$.

\section{Interfragmentary motion:}

Interfragmentary motion illustrated in Figure(5) between proximal and distal segments of condylar fracture of $2.3 \mathrm{~mm}$ plate model revealed $1.0608 \mathrm{~mm}$, While it revealed $0.2383 \mathrm{~mm}$ for the double $2.0 \mathrm{~mm}$ plates model, Lastly, results showed $0.436 \mathrm{~mm}$ for the rhombic plate model .

\section{DISCUSSION}

Finite element analysis (FEA) is a computational technique originally developed by engineers to model the mechanical behavior of structures such as buildings, aircraft, and engine parts. When a structure is loaded, its response can be described in terms of stress and strains within the structure. In a simple geometric structure created from homogeneous man made materials, stress and strain can be predicted with reasonable accuracy from analytical mathematical equations.
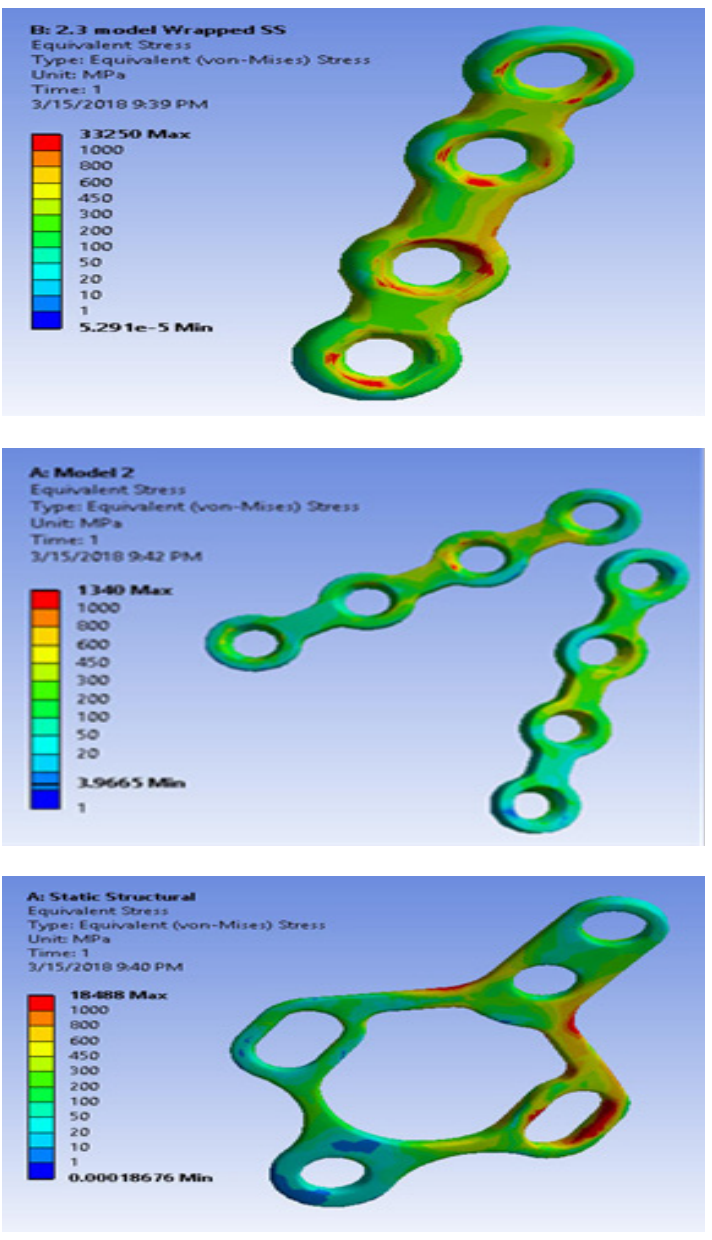

Fig. 3: Von Misses stresses for Titanium plates
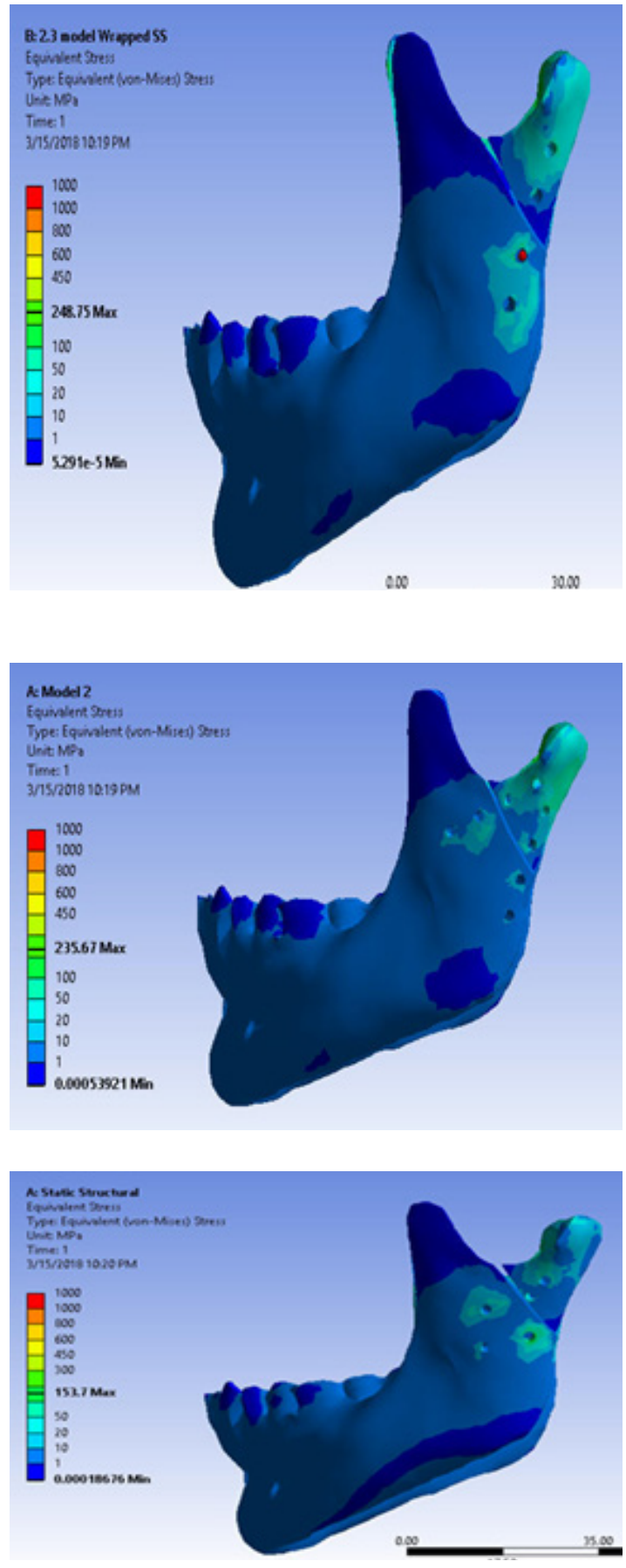

Fig. 4: VM stresses upon bone surrounding screws 

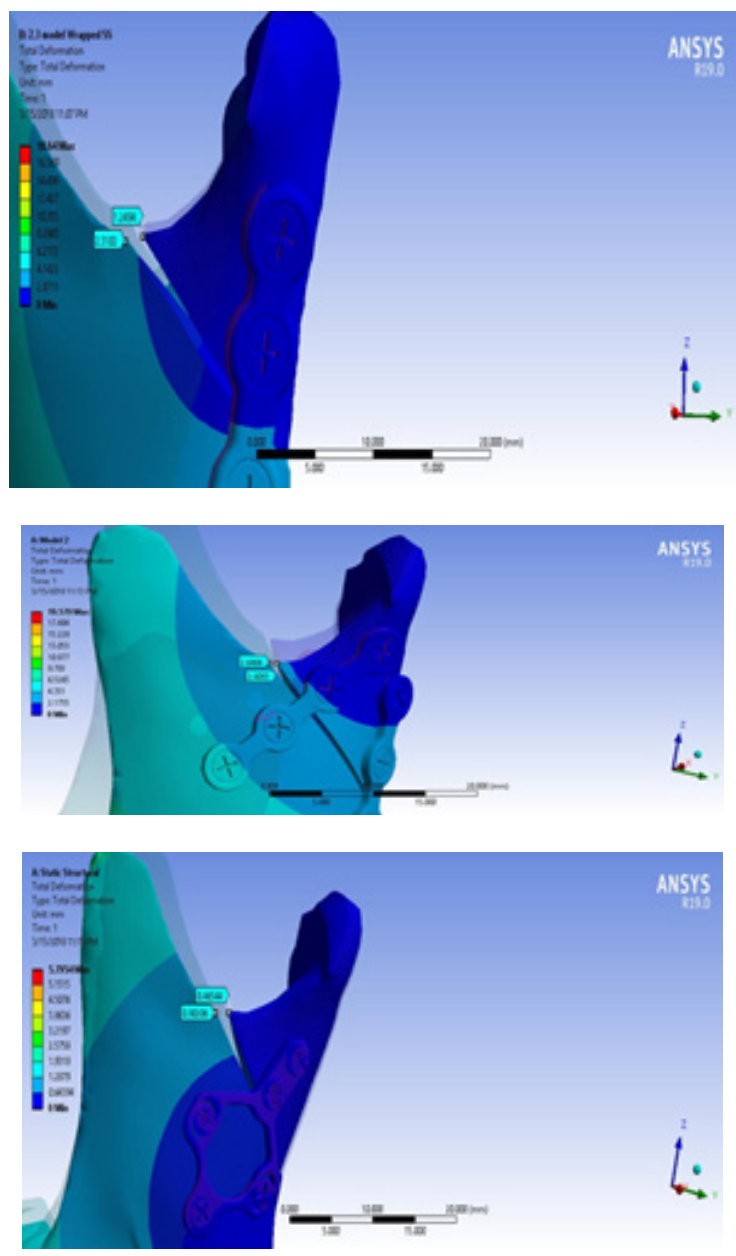

Fig. 5: Interfragmentary motion in $(\mathrm{mm})$ for the three patterns of fixation.

The ultimate purpose of a finite element analysis is to simulate mathematically the behavior of an actual engineering system. In other words, the analysis must be an accurate mathematical model of a physical prototype. In the broadest sense, this model comprises all the nodes, elements, material properties, element dimensions, boundary conditions, and other features that are used to represent the physical system. Three-dimensional finite element analysis of the mandible and condylar fracture performance under clenching force was performed using the finite element code ANSYS, which is widely available and well-documented finite element package. ANSYS is a general-purpose finite element program, that can be adapted to the solution of numerous engineering problems, including static/dynamic, structural analysis (both linear and nonlinear), heat transfer, and fluid problems, as well as acoustic and electromagnetic problems. Three numerical models were simulated to assessing the performance for the three types of the used plates.

In our study we paid attention to the effectiveness of various clenching tasks on the mandibular osteosynthesis and primary stability of fixation pattern.
It has been concluded that contralateral molar clenching task has the maximum effect on the primary stability of condylar osteosynthesis (11).

Results assumed that von misses stresses upon the different three plating configurations is in its maximum value for 2.3 plate $(750 \mathrm{MPa})$, $(650 \mathrm{MPa})$ for rhombic plate model configuration and the minimum value was for the double plating 2.0 configuration design(450 $\mathrm{MPa}$ ),However these results are not much important in the comparison between the three designs because of none of these plating designs showed bending or fracture under load in order that this values are much lower than yield stress (934 MPa) and fatigue limit(900-1000)MPa.

VM stresses of bone surrounding screws was least for the double plating techniques and the highest value was for 2.3 plate model configuration, none of them exceeded( 50 $\mathrm{MPa}$ ) .however the value for 2.3 plate model approaching the risk value and could result in healing problems, as It was concluded by Sugiura et al. that von misses stresses could be used as indicator for bone resorption, when stress in bone exceeds $50 \mathrm{MPa}$, this leads to bone resorption(15).

Inter fragmentary motion between the proximal and distal fracture segments is of primary concern in assessing the stabilization technique of osteosynthesis, Animal studies report that the needed mobility in bone fragments is 0.15 to $0.5 \mathrm{~mm}$ for achieving a good bone recovery(16)

2.3 single plate models showed the greater interfragmentary motion $(1.06 \mathrm{~mm})$ endangering physiological bone healing and subsequently fracture healing, while the double 2.0 plate design showed the least interfragmentary motion $(0.2 \mathrm{~mm})$.

Rhombic plate model design showed an accepted result in relation to the interfragmentary motion $(0.4 \mathrm{~mm})$ in comparison to single $2.3 \mathrm{~mm}$ plate.

\section{CONCLUSION}

- Double plating 2.0 design is the gold standard and the best method of fixation for subcondylar fractures provided that available space is enough for the application of the two plates.

- Rhombic plate is a biomechanically reliable osteosynthesis for sub-condylar fractures where there is no space available for two plate osteosynthesis.

- $\quad$ Single2.3 plate design is not a reliable treatment modality for(ORIF)treatment of cases of subcondylar fractures. 


\section{REFERENCES}

1. Aquilina P, Chamoli U, Parr WC, Clausen PD, Wroe S. Finite element analysis of three patterns of internal fixation of fractures of the mandibular condyle. The British journal of oral \& maxillofacial surgery. 2013;51(4):326-31.

2. Lauer G, Haim D, Proff P, Richter G, Pradel W, Fanghänel J, et al. Plate osteosynthesis of the mandibular condyle. Ann Anat. 2007;189(4):4127.

3. Powers DB. Classification of Mandibular Condylar Fractures. Atlas Oral Maxillofac Surg Clin North Am. 2017;25(1):1-10.

4. Kang DH. Surgical Management of a Mandible Subcondylar Fracture. Arch Plast Surg. 2012;39(4):284-90.

5. Lauer G, Haim D, Proff P, Richter G, Pradel $\mathrm{W}$, Fanghänel $\mathrm{J}$, et al. Plate osteosynthesis of the mandibular condyle. Annals of AnatomyAnatomischer Anzeiger. 2007;189(4):412-7.

6. Pileicikiene G, Surna A, Barauskas R, Surna R, Basevicius A. Finite element analysis of stresses in the maxillary and mandibular dental arches and TMJ articular discs during clenching into maximum intercuspation, anterior and unilateral posterior occlusion. Stomatologija. 2007;9(4):1218.

7. Parascandolo S, Spinzia A, Parascandolo S, Piombino P, Califano L. Two load sharing plates fixation in mandibular condylar fractures: Biomechanical basis. Journal of Cranio-MaxilloFacial Surgery.38(5):385-90.

8. Wagner A, Krach W, Schicho K, Undt G, Ploder O, Ewers R. A 3-dimensional finite-element analysis investigating the biomechanical behavior of the mandible and plate osteosynthesis in cases of fractures of the condylar process. Oral surgery, oral medicine, oral pathology, oral radiology, and endodontics. 2002;94(6):678-86.
9. de Jesus GP, Vaz LG, Gabrielli MF, Passeri LA, T VO, Noritomi PY, et al. Finite element evaluation of three methods of stable fixation of condyle base fractures. Int J Oral Maxillofac Surg. 2014;43(10):1251-6.

10. Kozakiewicz M, Swiniarski J. "A" shape plate for open rigid internal fixation of mandible condyle neck fracture. Journal of Cranio-Maxillofacial Surgery. 2014;42(6):730-7.

11. Hijazi L, Hejazi W, Darwich MA, Darwich K. Finite element analysis of stress distribution on the mandible and condylar fracture osteosynthesis during various clenching tasks. Oral Maxillofac Surg. 2016;20(4):359-67.

12. Hubbard BA, Muzaffar AR. Book Review: Atlas of Craniomaxillofacial Osteosynthesis: Microplates, Miniplates, and Screws. SAGE Publications Sage CA: Los Angeles, CA; 2012.

13. Hubbard BA, Muzaffar AR. Atlas of Craniomaxillofacial Osteosynthesis: Microplates, Miniplates, and Screws. The Cleft PalateCraniofacial Journal. 2012;49(3):380-.

14. El Halawani1M GN, Ayad2PhD SS, Darwish2PhD SA, Hassan2PhD RS. EVALUATION OF RHOMBIC THREE DIMENSIONAL PLATE IN TREATMENT OF MANDIBULAR SUBCONDYLAR FRACTURES IN ADULT PATIENTS FROM ALEXANDRIA. Alexandria Dental Journal. 2017;42:56-61.

15. Sugiura T, Horiuchi K, Sugimura M, Tsutsumi S. Evaluation of threshold stress for bone resorption around screws based on in vivo strain measurement of miniplate. J Musculoskelet Neuronal Interact. 2000;1(2):165-70.

16. Çimen E, Önder ME, Cambazoglu M, Birant E. Comparison of Different Fixation Types Used in Unilateral Mandibular Condylar Fractures: An In Vivo Study With New Biomechanical Model. Journal of Craniofacial Surgery. 2016;27(5):127781. 